\title{
Prospectives on membrane perceptions of temperature
}

\author{
Prasanna Mohanty \\ INSA Honorary Scientist, Functional Ecology at RPRC, Bhubaneswar - 751015 \\ Professor on Courtesy, DAVV, Indore - 452 001, India
}

\section{ABSTRACT}

Temperature is ubiquitous in all aspects of energetics and nearly all biological responses are quantitatively affected by temperature. While its fundamental role in contributing to enthalpy and entropy forms the foundation of thermodynamics, pinpointing a specific mechanism for temperature sensing is another matter. This note discusses the possibility, based on some studies and trends. [Physiol. Mol. Biol. Plants 2008; 14(3) : 273-275]

Bowler and Chua (1994) pointed out that for successful and sustainable existence, the plants of all forms need to coordinate their developmental changes and tandemly sense and respond to environmental fluctuations. There are several signals, both internal and external, that are continually perceived and responded to by plants (Trewavas and Malho, 1997; Trewavas, 2000). These internal and external stimuli vary from time to time in intensity and quality, carry regulatory information, which, in turn, is transduced through networks of signaling throughout the plant. The elements of the several signal transduction pathways, including multicomponent pathways are now well recognized and well characterized (Bowler and Chua, 1994; Stock and Da, 2000; Suzuki et al., 2000; Stock et al., 2000).

\section{Signal Perceptions: Temperature sensing in plants}

Plants need to resist, tolerate and acclimate to various environmental stresses. The initial step in the stress acclimation is the perception of stress signal by the sensor(s). Some of the sensing and signal transducing systems appear to be stress specific. I restrict the discussion here to the roles played by the physical state of the plant cell membranes in sensing temperature.

Murata and Los (1997) correlated the temperature perception in plant cells with fluidity or reciprocal viscosity of the membranes. A lowering of growthtemperature from $35^{\circ} \mathrm{C}$ to $22{ }^{\circ} \mathrm{C}$, say by $15{ }^{\circ} \mathrm{C}$, the cyanobacterial cells arrested their growth, stopped the synthesis of membrane fatty acids for several hours and membrane lipids were desaturated to a certain level of unsaturation, after which the cells resumed growing at low temperature. The enhanced level of desaturation was linked to the up-regulation of desaturases genes. Conversely, an up-shift of temperature caused a decrease in the levels of unsaturation in membrane lipid fatty acids as well as enhanced de-novo synthesis of saturated fatty acids in the cyanobacterium Synechosystis. Further, the rigidity of membrane lipids would inflict irreversible photoinhibition causing cell death, which is not linked to chlorosis or necrosis (Alakhverdiev et al., 2005). These authors demonstrated that the Synechosystis desA-/des D- mutant, lacking desaturases, suffered more severe, irreversible, irreparable photoinhibition under prolonged irradiation at low temperature than the wild type. Similarly, in higher plants, when the levels of saturated molecular species in the phosphatidyl glycerol (PG) were reduced by gene manipulation, the chilling-sensitive plants became more resistant to low temperature (Murata et al., 1992). Sommerville and colleagues showed that in Arabidopsis and its mutants for fatty acid desaturases (fad), the growth temperature modulated the membrane lipid composition and their degree of unsaturation, the ratio of unsaturation/saturation, by controlling desaturase activities at several steps in the lipid biosynthesis pathways and inter compartmental fluxes between cytosol and organelles (Falcone et al., 2004). In short, since the degree of unsaturation of membrane lipids influences the membrane fluidity, low temperature appears to decrease the fluidity as well as enhance the expression of desaturase genes that put double bonds 
into the membrane lipids to counter or compensate the decrease in fluidity. In the regulatory sense, one may conjecture that the physical compositional state of membranes senses the change in growth temperature (Wada and Murata, 1990; Wada et al., 1990). Changes in ambient temperature or osmolarity would cause fluctuations in membrane' fluidity that in turn could trigger regulatory functions like up or down regulation of genes (Los and Murata, 2004). However, how the fluidity state of membrane senses the threshold temperature or the turgor perceives the signals needs to be understood.

\section{Hydrogenation of Membrane Lipids}

Vigh et al. (1993) showed that the permeaplasts prepared from Synechosystis cells grown around $30^{\circ} \mathrm{C}$, the membranes could be hydrogenated by using palladium (Pd) hydride catalyst. Such hydrogenation changed, for some reason, the saturation level only of plasma membrane but not the thylakoid membranes and only that of major lipids. But soon after such hydrogenation of the major lipids of the plasma membranes, the mRNA levels of desaturases increase, and after $6 \mathrm{~h}$, the gene expression of desaturases increased to about 10 fold higher than the initial level. The result was similar to lowering of growth temperature by $15^{\circ} \mathrm{C}$. This was the closest to a direct demonstration of the change in fluidity of plasma membrane imposed by hydrogenation altering the expression of membrane bound enzymes and the physical state of membrane being linked to perception of temperature. Several genes that respond to temperature changes seemed to be controlled by the physical state of the membranes (Vigh et al., 1998). Modulation of the membrane physical state following a heat shock enhanced the expression of genes of heat shock proteins and other genes. The physical state of the thylakoid membranes of Synechosystis were altered by lowering the growth temperature or by treatment with benzyl alcohol. Such changes in fluidity of thylakoid membranes enhanced thermo-stability of photosynthetic membranes and activation of small heat shock proteins like groESL, dnaK, Cpn 60 and especially hsp17 (Horvath et al., 1998). There was direct correlation between thylakoid fluidity as visualized by monitoring fluorescent probe anisotropy and maximal activation of heat shock proteins. The hsp17 was recognized as a fluidity gene (Horvath et al., 1998) and the Synechosystis hsp17 protein functioned as heat stress stabilizing factor, as it helped in refolding of heat denatured proteins as a member of the chaperon family (Torok et al., 2001).
From these studies, it became evident that the thylakoid and not the cytoplasmic membranes could be the biological 'thermosensor' in plants. It is interesting to note that the state transitions (Allen, 2003) that regulate the balancing of absorbed quanta between two photosystems also serve as an "early reporter" of stress signals including the high temperature stress (Joshi et al., 1993). The important question is how the physical state of a membrane perceives a signal. The fluidity changes in the bulk of the membrane, say plasma membrane, to 'sense' the temperature shift signal would be unlikely. Murata's group assumed that the change in the phase behavior of the "micro domain" of the membrane would bring about conformational changes in membrane protein and that, in turn, would lead to the signal transduction involving protein phosphorylation and de-phosphorylation events (Los and Murata, 2004). This is what happens in state transition and we may recall the observation that drought-induced loss of photosynthesis is linked to the loss of thylakoid membrane bound ATP synthase (Boyer, 1990).

The concept of plant cell membranes as sensors is not new. The plasmamembranes serve as platforms for receptors of internal and external signals mediating the role of growth regulators and hormones, developmental signals, pathogens and minerals. Turgor serves as a signal for growth and cell division. The membrane potentials mediate regulation of fluxes and the pumping of ions in and out of cells. Several years ago we found that the drought sensitive and drought resistant varieties of wheat had differential values of diffusional membrane potentials (Amin and Mohanty, unpublished observations). The direct role of phosphatidyl glycerol (PG), a native constituent of thylakoid membranes, has been shown to be essential for the functionality of electron flow at the PSII reaction centre (Gombos et al., 2002) and the maintenance of photosynthetic machinery (Sakurai et al., 2003). The emerging roles of membranes and membrane constituents hold challenges for future research in plant membrane biology and biophysics.

\section{ACKNOWLEDGEMENTS}

My sincere thanks to N. Raghuram, Sujata Mishra and Venkateswarlu for their help in the preparation of this note. INSA is acknowledged for the Honorary Scientist affiliation at RPRC, Bhubaneswar and DAVV, Indore for Courtesy visiting Professorship. 


\section{REFERENCES}

Alakhverdiev, S.I., Sevetkova, N., Mohanty, P., Moon, B.Y., Szolontai, B., Dehviecty, M. and Murata, N. (2005). Irreversible photoinhibition of oxygen evolving activity of PSII is caused by impaired processing of the precursor of $\mathrm{D} 1$ protein in Synechosystis. Biochim. Biophys. Acta 1708: 342-351

Allen, J.F. (2003) State Transition -a question of balance. Science 299: 1530-1532.

Bowler, C. and Chua, N-H (1994) Emerging themes of Plant Signal transduction. Plant Cell 6: 1529-1541.

Boyer, J.S. (1990). Photosynthesis in dehydrating plants. Bot. Mag. Tokyo Special Issue 2: 73-85.

Falcone, D.L., Ogas, J.P., Sommerville, C. (2004). BMC Plant Biology 4: 17.

Gombos, Z, Várkonyi, Z., Hagio, M., Iwaki, M., Kovács, L., Masamoto, K., Itoh, S. and Wada, H. (2002). Phosphatidylglycerol requirement for the function of electron acceptor plastoquinone QB in the photosystem II reaction center. Biochemistry 41: 3796-3802

Horváth I, Glatz A, Varvasovszki V, Török Z, Páli T, Balogh G, Kovács E, Nádasdi L, Benkö S, Joó F, Vígh L. (1998). Membrane physical state controls the signaling mechanism of the heat shock response in Synechocystis PCC 6803: identification of hsp17 as a "fluidity gene". Proc. Natl. Acad. Sci. USA., 95(7): 3513-3518.

Joshi MK, Desai H and Mohanty P (1995). Temperature dependent alterations in the pattern of photochemical and non photochemical quenching and associated changes in the Photosystem II condition of the leaves. Plant Cell Physiol. 36: 1121-1127.

Los, D.A. and Murata, N. (2004). Membrane Fluidity and its role in the perceptions of environmental signals. Biochim. Biophys. Acta 1666: 142-147

Murata, N, Los, D.A. (1997). Membrane Fluidity and Temperature Perception. Plant Physiol. 115: 875-879.

Sakurai, I., Hagio, M., Gombos, Z., Tyystjarvi, T., Paakkarinen, V., Aro, E.M. and Wada, H. (2003). Requirement of Phosphatidylglycerol for maintenance of photosynthetic Machinery. Plant Physiol. 133: 1376-1384.
Stock, J. and Da, R.S. (2000). Signal Transduction: Response regulators on and off. Curr. Biol. 10: R420-R424.

Stock, A.M., Robinson, V.L., and Gourdeau, P.N. (2000). Two component signal transduction. Annu. Rev. Biochem. 69: $183-215$.

Suzuki, I., Los, D.A., Kanaseki, Y., Mikami, K. and Murata, N. (2000). The pathway of signal perception and transduction of low temperature signal in Synechocystis. EMBO J 19: 1327-1334.

Török, Z., Goloubinoff, P., Horváth, I., Tsvetkova, N.M., Glatz, A., Balogh, G., Varvasovszki, V., Los, D.A., Vierling, E., Crowe, J. and Vígh, L. (2001). Synechocystis HSP17 is an amphitropic protein that stabilizes heat-stressed membranes and binds denatured proteins for subsequent chaperone-mediated refolding. Proc. Natl. Acad. Sci. USA. 98: 3098-3103.

Trewavas, A.J. (2000). Signal perception and Transduction. In: Biochemistry and Molecular Biology of Plants (B. Buchannan, W. Gruisem and R. Jones, Editors). American Society of Plant Physiology pp 530-587.

Trewavas, A.J. and Mahlo, R. (1997). Signal perception and transduction: the origin of the phenotype. Plant Cell 9: 1181-1186.

Vigh, L., Los, D.A., Horvath, I. and Murata, N. (1993). The primary signal in the biological perception of temperature: Pd-catalyzed hydrogenation of membrane lipids stimulated the expression of des-A gene in Synechosystis PCC6803. Proc. Natl. Acad. Sci. USA, 90: 9090-9094.

Vigh, L., Maresca, B. and Harwood, J.L. (1998). Does the membrane physical state control the expression of heat shock and other genes? Trends Biochem. Sci. 23: 369 374.

Vigh, L., Horvath, I., Marseca, B. and Harwood, J.L. (2007). Can the stress proteins responses be controlled by membrane lipid therapy? Trends Biochem.Sci. 32(8): 357-363.

Wada, H., Gombos, Z. and Murata, N. (1990). Enhancement of chilling tolerance of a cyanobacterium by genetic manipulation of fatty acid desaturation. Nature 347: 200-203.

Wada, H. and Murata, N. (1990). Temperature induced changes in fatty acid composition of the cyanobacterium Synechosystis PCC 6803. Plant Physiol 92 (4): 10621069. 